\title{
A Geometric Morphometrics Study of Stigma-Anther Polymorphism in the Tropical Distylous Palicourea padifolia (Rubiaceae)
}

\author{
Angélica María Hernández-Ramírez ${ }^{1}$, José A. Aké-Castillo ${ }^{*}$ \\ ${ }^{1}$ Centro de Eco Alfabetización y Diálogo de Saberes, Universidad Veracruzana, Veracruz, Mexico \\ ${ }^{2}$ Instituto de Ciencias Marinas y Pesquerías, Universidad Veracruzana, Veracruz, Mexico \\ Email: aake@uv.mx
}

Received 2 March 2014; revised 8 April 2014; accepted 21 April 2014

Copyright (C) 2014 by authors and Scientific Research Publishing Inc.

This work is licensed under the Creative Commons Attribution International License (CC BY). http://creativecommons.org/licenses/by/4.0/

(c) $\underset{\mathrm{EY}}{\mathrm{F}}$ Open Access

\section{Abstract}

Distyly is a floral polymorphism with long-styled flowers and short-styled flowers. Traditionally, floral traits in distylous species have been studied as a variable composed of several linear measurements. We proposed the use of a geometric morphometric approach to studying flower shape and entire flower design variation (including stigma-anther polymorphism) between morphs in Palicourea padifolia. The geometric morphometric approach allowed us to preserve the integrity of the floral form and to project the floral features on the same scale. Moreover, the visualization of a grid deformation allows us to describe shape differences between morphs as well as to estimate the variance-covariance matrix among floral traits. In this study, we demonstrated that flower shape and entire flower design differed between morphs. Intra- and inter-morph variations in the flower size were observed. The flower size has an effect on the anther position between morphs and among individuals. An association between flower shape and flower size was observed in both morphs. A pattern of floral features co-variation between the morphs was demonstrated in the species. In P. padifolia both morphs seemed to be internally coherent with respect to the developmental processes that produce flower shape variation. Changes in floral traits associated with flower size seemed to be more complex than those in the simple uniform expansion of the floral trait positions analogous between morphs. The observed pattern of co-variation of floral features between morphs suggested that flower base shape would be an additionally ancillary trait linked to the stigma-anther polymorphism in the species.

\footnotetext{
${ }^{*}$ Corresponding author.
}

How to cite this paper: Hernández-Ramírez, A.M. and Aké-Castillo, J.A. (2014) A Geometric Morphometrics Study of Stigma-Anther Polymorphism in the Tropical Distylous Palicourea padifolia (Rubiaceae). American Journal of Plant Sciences, 5, 1449-1458. http://dx.doi.org/10.4236/ajps.2014.510160 


\section{Keywords}

\section{Ancillary Traits, Flower Shape and Entire Flower Design, Heterostyly, Landmark, Procrustes}

\section{Introduction}

Heterostyly is a genetically controlled floral polymorphism in which plant populations are composed of two or three floral morphs that differ reciprocally in the position of stigmas and anthers in flowers, as well as a suite of ancillary floral traits associated with the polymorphism [1]-[3]. Floral polymorphism is often associated with an incompatibility system that prevents self- and intra-morph fertilization [1] [2]. Nonetheless, variations in the precision of reciprocal sexual organs position and the strength of the incompatibility system are not uncommon in heterostylous plants, providing self- and intra-morph mating opportunities [3] [4].

In the case of species with two floral morphs, i.e., distylous species, populations contain plants that produce long-styled flowers (LS morph) with the stigmas positioned above the anthers or short-styled flowers (SS morph) with the anthers positioned above the stigmas [1] [2] [5]. Several developmental pathways produce differences in the stigma and anther position between floral morphs, and these have been documented in distylous species [1] [2]. Specifically, differences in growth rates and inhibition times of stigma and anthers heights at different floral bud sizes cause differences in organ positions between floral morphs [6]-[8].

Under an evolutionary perspective, approach herkogamy morphology (i.e., stigmas positioned above anthers) has been proposed as the evolutionary precursor to heterostyly, which corresponds to the LS morph [5]. According to Lloyd and Webb [5], the evolution of the SS morph involves a mutation in style height becoming reverse herkogamy morphology (i.e., with anthers positioned above the stigma). A fitness advantage allows the new mutation to spread through population; subsequently a second mutation arises that adjust anther height to match style height of the approach herkogamous flowers [5].

Traditionally, floral traits in distylous species have been studied as a variable composed of several linear measurements [1] [2] [5] [9] [10], providing valuable information about the floral morphology in distylous species. Nonetheless, traditional measures of floral traits have not preserved the physical integrity of the floral form [11].

A geometric morphometric technique allows us to study directly the shape of an object [12] [13], rather than indirectly via fragmentary linear measurements, as a cohesive whole through the adoption of a coordinate system and the allocation of all shapes into that coordinate system [11]. Moreover, the visualization of a grid deformation allows us to describe shape differences between objects as well as to estimate the variance-covariance matrix among particular features [11].

Palicourea padifolia is a distylous species with ancillary floral traits linked to the stigma-anther polymorphism [8]-[10]. Variation in the precision of sexual organs position between floral morphs (i.e., reciprocal herkogamy) has reported for the species [9] [10]. The stigma and the anthers are imbedded into the flower structure subject to developmental processes that produce floral shape variation within floral morphs [8] and selective forces that potentially promote the relative spatial matching of sexual organs position between floral morphs [9] [10]. These characteristics represent a challenge for understanding the stigma-anther polymorphism in the species. Through geometric morphometrics approach, we incorporate the study of the shape, size and position of floral traits within and between floral morphs as a way to understand floral shape variation in the stigma-anther polymorphic Palicourea padifolia.

Specifically, under the geometric morphometric approach, we studied the flower shape and entire flower design variation between floral morphs in P. padifolia. We used the LS morph flowers as the floral form of reference (control) because it resembles approach herkogamy morphology; i.e. floral form ancestor of heterostylous taxa following Lloyd and Webb [5]. The specific questions addressed were: Was there any difference in the flower shape (corolla contour) between floral morphs in $P$. padifolia? Was there any difference in the entire flower design (including stigma-anther polymorphism) between floral morphs in the species? Did flower size contribute to explaining the differences in the stigma and anther position between floral morphs? Was there any association between flower shape and flower size in both floral morphs? Did a pattern of floral feature co-variation exist between morphs? We hypothesized that floral morphs would differ in flower shape and entire 
flower design, because flowers grow as an integrated structure [11]. Flower size would contribute to explaining anther position in the species, because the filaments are adnated to the corolla tube [7] [9] [14]. Flower shape and flower size would be associated in the species; due to differences in development pathways cause differences in the organs position between floral morphs in the species [8]. A pattern of floral feature co-variation would exist between floral morphs, due to that ancillary traits are linked to the stigma-anther polymorphism in the species [1] [2] [7] [8].

\section{Materials and Methods}

\subsection{Study Area}

We conducted the field study in a fragmented landscape of a tropical montane cloud forest near Xalapa City, in Veracruz, Mexico (19 $30^{\prime} \mathrm{N}, 96^{\circ} 57^{\prime} \mathrm{W}$; $1225 \mathrm{~m}$ a.s.l.). Data collection was conducted in June in 2005, when $P$. padifolia bloomed.

\subsection{Study Species}

Palicourea padifolia (Roem. \& Schult.) C.M. Taylor and Lorence (Rubiaceae) is a common tropical shrub in middle-elevation cloud forests from southern Mexico to Panama. Flowering plants produce large floral displays (30 - 80 inflorescences, each bearing 80 - 90 floral buds). Flowers are yellow with tubular corollas and remain open for one day. The LS morph has significantly shorter corollas (mean \pm S.E.; $13.5 \pm 0.18 \mathrm{~mm}$ ) than the SS morph $(16.4 \pm 0.14 \mathrm{~mm})$ and the filaments are adnate to the corolla tube [10]. Anthers of the LS flowers have ca. 1.3 times more pollen and are 6.5 times smaller than those of the SS flowers. The species is completely intra-morph incompatible with 1:1 proportion of floral morphs [15]. Hummingbirds are the main pollinators in the species. Insects have been observed collecting pollen but their visitation frequency is lower than hummingbird visitation [15]. Ornelas et al. [16] documented that LS morph flowers secreted more nectar after repeated removals (mean \pm S.E., $13.99 \pm 0.77 \mu \mathrm{L}$ /flower) than SS morph flowers (10.24 $\pm 0.85 \mu \mathrm{L} /$ flower). The SS morph flowers had more nectar before noon than the LS morph flowers, but such differences disappeared in the afternoon [16].

Differences in the flower morphology among populations have been reported for the species [10]. Thus, we decided to study the flower shape and entire flower design variation between floral morphs in one population to control additional sources of floral morphological variation in the species.

\subsection{Study Design}

We randomly selected 20 plants per floral morph and collected 4 apical flowers from four inflorescences in similar position in the plant (1.5 m of height) to analyze the intra- and inter-morph variation in floral traits. To avoid the driest hours and thus flower deformation, we collected flowers of each plant from 900 to $1100 \mathrm{hrs}$ in one day. The flowers were carefully transported and processed in the laboratory during the following two to three hours. Flowers were longitudinally dissected and photographed using a stereoscopic microscope and a digital camera Nikon E950 of 7 megapixels. The photographs were kept in jpg format in high quality (1600 × 1200 dimensions). We used geometric morphometrics based on Procrustes methods to study flower shape and entire flower design variation between floral morphs in P. padifolia [12] [13]. Geometrics morphometrics is a method that uses points called landmarks that can be use in statistical analysis based on Cartesian landmark coordinate for the study of the shape [17]. Procrustes superimposition minimizes the differences among the configuration of landmarks (which define shape) by rotating them to minimize the summed squared distances between homologous landmarks [17] [18].

\subsection{Flower Shape and Entire Flower Design}

To study flower shape and entire flower design between floral morphs in the species, we digitalized six natural marks corresponding to the corolla contour in each flower (Figure 1). We used the program makefan6 to generate artificial marks to ensure covering the entire form of the corolla. We selected eight marks corresponding to the corolla tube and the flower base (landmarks 3 - 6 and 10 - 13; Figure 1), totaling 14 landmarks to describe the flower shape variation between floral morphs in the species. 


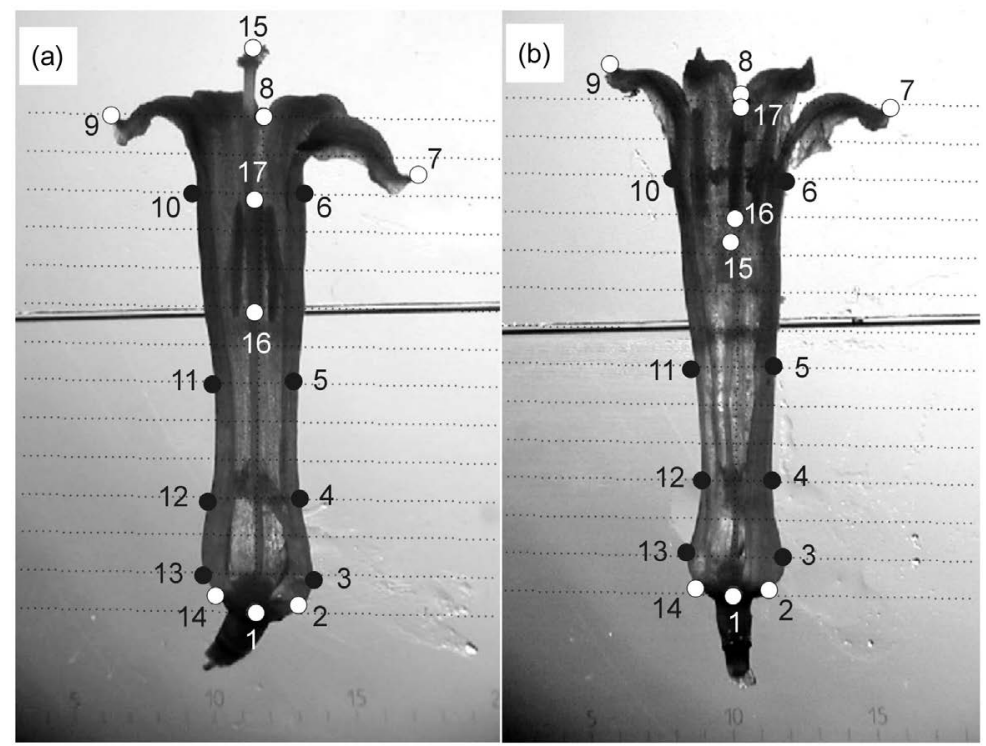

Figure 1. Landmarks for corolla shape $(1$ - 14) and flower shape (1 - 17) White circles indicate natural marks, black circles are landmarks generated by makefan program. (a) LS morph, and (b) SS morph.

We digitalized additional three natural marks corresponding to the stigma position (15 landmark), and the anther position (16 and 17 landmarks; Figure 1) in each flower, totaling 17 landmarks to compare the entire floral design including the stigma-anther polymorphism effect between floral morphs in the species

We digitalized the landmarks using TPSdig ver. 1.4 program [18] and we used the Integrated Morphometrics Package (IMP) specifically makefan6, Coorgen6f, PCAGen6n, CVAGen6k, TwoGroup, Regress6k, PLSmaker compiled software tools for the different procedures in the analyses [17]-[19].

To generate coordinates, we used Coorgen6f program using procrustes superimposition, which allowed us to study the magnitude and direction of differences between forms at each landmark through the deformation grids based on the partial warps. The partial warps, which represent the non-uniform deformation component were calculated and computed as eigenvectors extracted from the bending-energy matrix. The contribution of each partial warp to the total deformation is indicated by a score, which is a two vector dimension that shows the direction in the deformation grid. These scores can be used to perform subsequent multivariate analyses and they represent the correct tangent space measure of distance [17] [20] [21]. The centroid size (CS) is a measure of the geometric scale of the flower size [17].

\subsection{Differences in the Flower Shape and Entire Flower Design between Floral Morphs}

Partial warp scores were used in a principal component analysis (PCA) and canonical variates analysis (CVA) to explore the differences between floral morphs considering first only flower shape (corolla contour) and later entire flower design including stigma-anther polymorphism (PCAGen6n and CVAGen6k programs). We tested significant differences in the flower shape or entire flower design between floral morphs using the program TwoGroup [17].

\subsection{Effect of Flower Size on the Stigma and Anther Position}

Generalized linear models were used to validate the statistical significance of flower size on the stigma and anther position between floral morphs in the species. First, the intra- and inter-morph variation in the flower size (i.e. CS) was analyzed using a generalized linear model. The floral morph was treated as a fixed factor and the plant was nested within floral morph factor. Second, the effect of flower size (CS) on the stigma and anther position (partial warps scores corresponding to these landmarks) between floral morphs was tested using generalized linear models. In the models, the floral morph was treated as fixed factor, the plant was nested within floral morph factor, and the flower size (CS) was used as a covariate. The response variables of the models were the 
stigma position or anther position in flowers (partial warps scores corresponding to these landmarks). The significance of the factors and their interaction with the covariate was tested using a backward suppression of nonsignificant effects [22]. They were tested and included in the residual deviance when they were not significant, using an information criterion (AIC). The over dispersion of the residual deviance was corrected by scaling the residual deviance divided by the number of degrees of freedom [22]. These statistical analyses were done using R program [23].

\subsection{Flower Shape and Flower Size Association between Floral Morphs}

The relationship between the flower shape and flower size was explored using the program Regress6k. We did a multivariate regression using flower shape variables (partial warps + uniform components) and the centroid size (CS), as a measure of the geometric scale of the flower size [17].

\subsection{Pattern of Co-Variation of Floral Features}

We applied a Partial Least Square (PLS) analysis using the program PLSMaker to analyze the co-variation of floral features between floral morphs in P. padifolia.

\section{Results}

\subsection{Differences in the Flower Shape and Entire Flower Design between Floral Morphs}

The PCA resulted in a plot in which the floral morphs were not easily distinguishable based on their flower shape (plot not shown: the variance explained by the first component was 0.51). The CVA was a technique that discriminated the two floral morphs in a better way (significant canonical variable MANOVA Axis $1, \lambda=0.21$, $\left.\chi^{2}=230.90, P<0.0001\right)$. Only two specimens of the LS morph were assigned to the SS morph based on their flower shape. The difference between floral morphs was significant according to the Goodalls F-test $(F=28.33$, $P=0.01$, Figure 2(a)).

When we incorporated the entire flower design (including stigma-anther polymorphism) in the analysis, the PCA resulted in a plot with the two floral morphs were clearly separated. The first principal component accounted for most of the morphological variation in the data set (92\% of the total variability), indicating significant differences in the entire flower design between floral morphs (Goodalls F-test: $F=1558.32, P=0.01$; Figure 2(b)).

\subsection{Effect of Flower Size on the Stigma and Anther Position}

The generalized linear model results indicated significant differences in the flower size (CS) between floral morphs $(F=88.87, P<0.0001)$ and among plants $(F=3.83, P<0.0001)$, which means intra- and inter-morph variation in the flower size in the species (Mean \pm SE; LS morph $=24.8 \pm 0.12$ and SS morph $=27.13 \pm 0.10$ ). We observed that the flower size did not contribute to explaining the differences in the stigma position between floral morphs and among individuals (Morph $F=6902.33, P<0.0001$; plant nested in morph $F=3.12, P<$ 0.0001 ; and covariate $F=0.23, P=0.62$ ). Nonetheless, the flower size contributed to explaining the differences in the anther position between floral morphs and among individuals (Morph $F=477.31, P<0.0001$; plant nested in morph $F=3.17, P<0.0001$; and covariate $F=6.13, P=0.01$ ).

\subsection{Flower Shape and Flower Size Association between Floral Morphs}

We observed a significant correlation between the flower shape and flower size in both floral morphs in the species (LS morph Rao's F-score $=2.98$ Wilk's $\lambda=0.35, P=0.0003$, and SS morph Rao's F-score $=3.36$, Wilk's $\lambda$ $=0.33, P<0.0001)$. According to the grid deformation, in larger flowers of both LS and the SS morphs, we observed a displacement of the stigma position (landmark 15) toward the flower base (landmark 1). Only in the SS morph the anther position presented a displacement toward the flower base in larger flowers (landmark 17; Figure 3(a), Figure 3(b)).

\subsection{Pattern of Co-Variation of Floral Features}

The analysis of PLS resulted in a significant correlation of floral features between floral morphs (vector correla- 


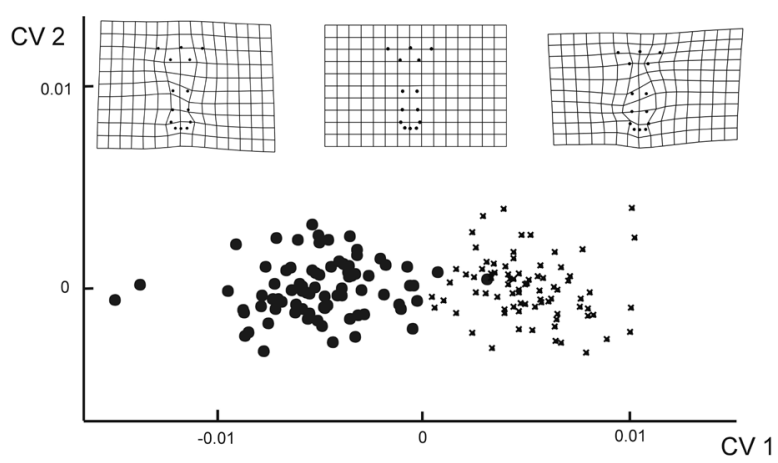

(a)

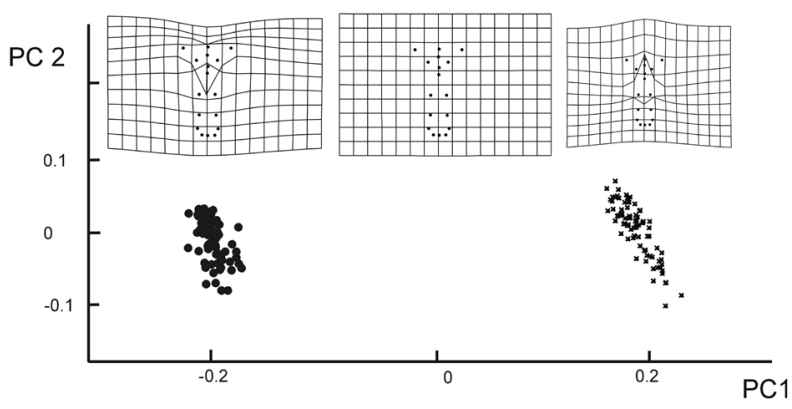

(b)

Figure 2. (a) CVA of corolla shape. (b) PCA of flower shape. Along CV1 and PC1 the deformation grids are shown. The grids in the center represent the reference form, the others represent the extreme points of the plots. Circles are the LS morphs, and crosses are the SS morphs.

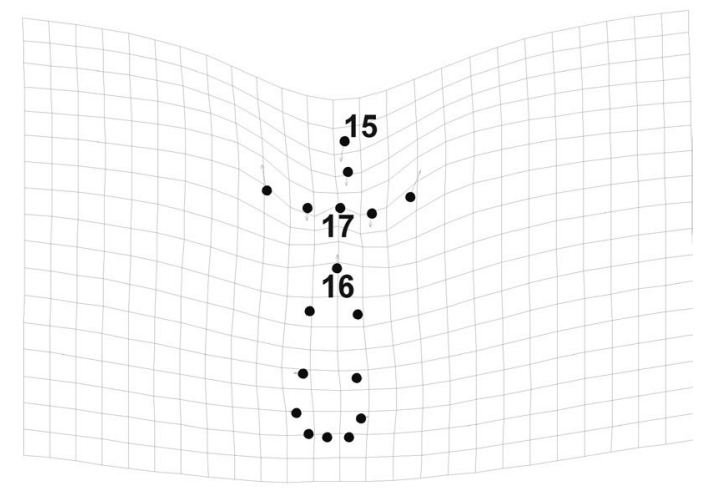

(a)

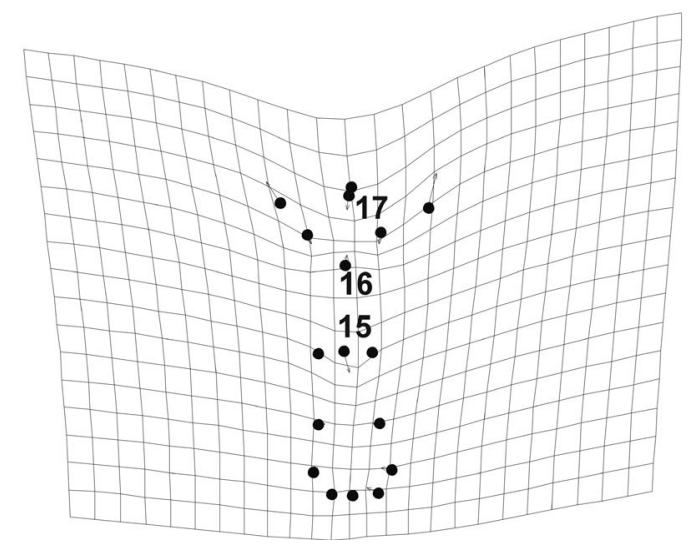

(b)

Figure 3. Relationship between the flower shape and flower size (centroid size, log-transformed). (a) The LS morph and (b) SS morph. Observe reduction of stigma length in both morphs (landmark 15) and reduction of the anther height in the LS morph (landmark 17) in larger forms.

tion was $0.64, r^{2}=0.41, P=0.03$ using 10,000 permutations). In the species, we observed that the majority of the floral features of both floral morphs co-varied in the same direction. Nonetheless, in the LS morph anther landmark 16 moved downward, while landmark 17 did not change, whereas in the SS morph landmark 17 moved upward, while landmark 16 did not change (Figure 4). Moreover, the set of landmarks corresponding to the base of the flowers co-varied in opposite direction between floral morphs (landmarks 2, 3, 4, 12, 13 and 14); i.e., in the LS morph the flower base got thinner, while in the SS morph the flower base got wider (Figure 4).

\section{Discussion}

Through geometric morphometric approach, we demonstrate that floral morphs differ in flower shape (corolla contour) and entire flower design (including stigma-anther polymorphism) in P. padifolia (Figure 2). Empirical studies noted slight differences in the shape of the corolla between floral morphs in distylous species [1]. In this study we demonstrated that flower shape varied between floral morphs in the species using a statistical test based in data produced under a geometric morphometric approach, concurring with the hypothesis that floral morphs differ in flower shape as well as the entire flower design in the species. Moreover, floral morph discrimination was enhanced when we considered the entire flower design; i.e. including the stigma-anther polymorphism. This result concurs with the observed differential arrangement of reproductive organs that distinguish distylous species (primary diagnostic trait); i.e. two discrete classes of anther and stigmas positions between floral morphs in distylous species [2] [5]. 


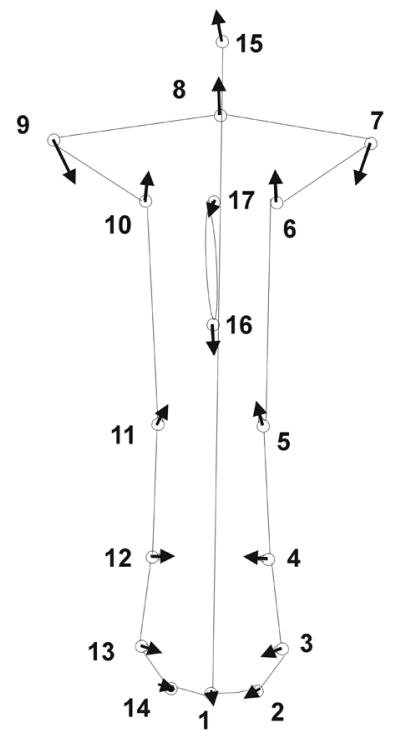

LS

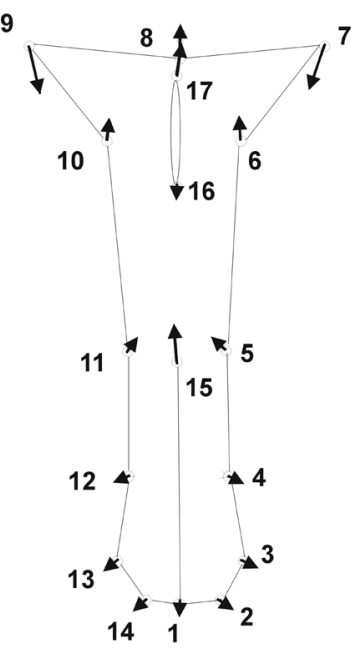

SS

Figure 4. Vectors on landmarks showing the co-variance pattern of floral features between the LS and the SS morphs.

Corolla size dimorphism has been reported in distylous species belonging to Rubiaceae family; i.e. Gaertnera vaginata [24], Guettarda scabra [6], Bouvardia ternifolia [7] [25], Psychotria chiapensis, Psychotria poeppigiana [7] [25], Psychotria nervosa [26], and Palicourea padifolia [9] [10]. Moreover, intra-morph variations in corolla size have been documented in Bouvardia ternifolia, Psychotria poeppigiana [25] and Palicourea padifolia [8]. In this study, we documented intra- and inter-morph variations in the flower size in P. padifolia, with the advantage that flowers were projected on the same scale and the physical integrity of the floral form was preserved. Hernández and Ornelas [9] described the relationship between corolla size and anther height in both floral morphs, whereas corolla size and stigma height were related only in the SS morph through linear measurements in the species. In this study, we corroborated the contribution of the flower size in explaining the anther position in the species; because of the filaments are adnated to the corolla tube. Nonetheless, contrary to Hernández and Ornelas [9], we did not observe any association between flower size and stigma position. This result was expected, because the development of the carpel is independent of the development of the corolla [14].

We hypothesized that flower shape and flower size would be associated in the species, because of differences in development pathways cause differences in the organs positions between floral morphs in P. padifolia. The observed relationship between the flower shape and the flower size in both floral morphs indicated an integrated association of the relative configuration and distances of the floral traits in the species. Furthermore, the grid deformation showed that large flowers of both morphs reduced the stigma position, whereas the anther position was reduced only in the SS morph in larger flowers (Figure 3(a), Figure 3(b)), indicating that the shape-size relationships were not merely allometric in $P$. padifolia. Changes in floral traits associated with flower size seemed to be more complex than the simple uniform expansion of the floral trait positions analogous between morphs. Previous studies documented several developmental pathways for achieving differences in the stigma and anther position between floral morphs in distylous species [6] [7] [27]. Specifically in P. padifolia, Hernández and Ornelas [8] described different patterns of development associated with the stigma and anther position in the species. They reported a positive allometric relationship between the stigma height and the floral bud elongation in the LS morph and a negative allometric relationship between the stigma height and the floral bud elongation in the SS morph [8]. Moreover, the anther height presented an isometric relationship with the floral bud elongation in the LS morph and a positive allometric relationship in the SS morph [8], indicating that differences between floral morphs in the stigma and the anther position were achieved in various ways during the development in the species. The results obtained in this study concur with the hypothesis that flower shape and flower size was associated in the species. Moreover, the shape-size relationship was not merely allometric in 
P. padifolia. Thus, differences in pathways of development cause differences in the organs positions between floral morphs in the species.

In $P$. padifolia both floral morphs seemed to be internally coherent with respect to the developmental processes that produce flower shape variation. The observed pattern of co-variation of floral features between floral morphs indicated that changes in the floral feature configuration occurred in a coupled way between floral morphs, which is a key to explain heterostyly syndrome (Figure 4). These results concur with the hypothesis that a pattern of floral feature co-variation would exist between floral morphs in the species, because ancillary traits are linked to the stigma-anther polymorphism in the species. The overall correspondence of the floral features observed between floral morphs in the species was not surprising, because the stigma-anther polymorphs in distylous species is usually accompanied by a suit of ancillary floral traits associated with the polymorphism [1] [2]. The study of stigmas (shape, length and orientation of the stigma lobes) and pollen (number, color, shape and size) characteristics of distylous species have received major attention [1] [2] [15] [28]. Nonetheless, this study showed that an inverse co-variation of the flower base shape occurred between floral morphs in P. padifolia. This result suggests that the flower base shape might be a floral feature linked to the dimorphism in the species, constituting an additional ancillary floral trait associated with the stigma-anther polymorphism. Moreover, the observed flower base shape co-variation between floral morphs has a potential functional significance in the species. For example, differential strategies of pollination attraction may occur between floral morphs in $P$. padifolia. A thin nectar receptacle in the LS morph may promote a continuous secretion of nectar in the LS flowers; whereas a wide nectar receptacle in the SS morph may promote an accumulation on nectar in the SS flowers. In this sense, Ornelas et al. [16] mentioned that the LS morph flowers secreted more nectar than the SS morph flowers during a day; whereas the SS morph flowers had more nectar available before noon than the LS morph flowers. In spite of nectar vanished over the time (after noon), the LS morph flowers were visited earlier than the SS morph flowers by hummingbirds [16]. Differences in pollinator behavior linked to nectar production have been associated with the ability of floral morphs to export or receipt pollen grains in the species [15] [16]. Thus, the flower base shape co-variation between floral morphs suggests that such floral trait might be subject to selective forces in the species.

\section{Conclusions}

In conclusion, the geometric morphometric approach allowed us to study the flower shape and entire flower design variation between floral morphs in P. padifolia. This approach allowed us to preserve the integrity of the floral form and to project the floral features on the same scale. Specifically, we demonstrated that flower shape as well as the entire flower design differed between floral morphs. The effect of flower size on anther position was corroborated in the species. The association of flower shape and flower size was demonstrated, indicating that the shape-size relationship was not merely allometric in the species. A pattern of co-variation of floral features was demonstrated, suggesting that flower base shape would be an additionally ancillary trait linked to the stigma-anther polymorphism in the species.

Integrating geometric morphometric analyses in the study of stigma-anther polymorphism, stigma-height polymorphism and enantiostyly would be a promising approach to understanding floral shape variation in polymorphic species.

\section{Acknowledgements}

Angélica Hernández-Ramírez thanks to Guillermo Angeles and Fernando Ortega-Escalona (Instituto de Ecología A.C.) for their laboratory facilities to conduct part of our research. J.A. Aké-Castillo thanks convenio MOD-ORD-70-08 PCI-1054-11-08 of Programa para el Fomento, Desarrollo y Consolidación de Científicos y Tecnólogos CONACYT-UV.

\section{References}

[1] Ganders, F.R. (1979) The Biology of Heterostyly. New Zealand Journal of Botany, 17, 607-635. http://dx.doi.org/10.1080/0028825X.1979.10432574

[2] Barrett, S.C.H. (1992) Evolution and Function of Heterostyly. Springer Verlag, New York. http://dx.doi.org/10.1007/978-3-642-86656-2 
[3] Barrett, S.C.H., Jesson, L.K. and Baker, A.M. (2000) The Evolution and Function of Stylar Polymorphism in Flowering Plants. Annals of Botany, 85, 253-265. http://dx.doi.org/10.1006/anbo.1999.1067

[4] Barrett, S.C.H. and Cruzan, M.B. (1994) Incompatibility in Heterostylous Plants. In: Williams, E.G., Knox, R.B. and Clarke, A.E., Eds., Genetic Control of Self-Incompatibility and Reproductive Development, Kluwer Academic Publishers, Dordrecht, 189-219. http://dx.doi.org/10.1007/978-94-017-1669-7_10

[5] Lloyd, D.G. and Webb, C.J. (1992) The Evolution of Heterostyly. In: Barrett, S.C.H., Ed., Evolution and Function of Heterostyly, Springer Verlag, New York, 151-178. http://dx.doi.org/10.1007/978-3-642-86656-2_6

[6] Richards, J.H. and Koptur, S. (1993). Floral Variation and Distyly in Guettarda scabra (Rubiaceae). American Journal of Botany, 80, 31-40. http://dx.doi.org/10.2307/2445117

[7] Faivre, A.E. (2000) Ontogenetic Differences in Heterostylous Plants and Implications for Development from Herkogamous Ancestor. Evolution, 54, 847-858.

[8] Hernández, A. and Ornelas, J.F. (2007) Development of Distylous Flowers and Investment of Biomass in Male and Female Function in Palicourea padifolia (Rubiaceae). Plant Biology, 9, 694-704.

http://dx.doi.org/10.1055/s-2007-965238

[9] Hernández, A. and Ornelas, J.F. (2003) Correlación morfo-específica en flores de Palicourea padifolia (Rubiaceae). Boletín de la Sociedad Botánica de México, 73, 35-41.

[10] Hernández, A. and Ornelas, J.F. (2007) Disassortative Pollen Transfer in Distylous Palicourea padifolia (Rubiaceae), a Hummingbird-Pollinated Shrub. Ecoscience, 14, 8-16. http://dx.doi.org/10.2980/1195-6860(2007)14[8:DPTIDP]2.0.CO;2

[11] Richtsmeier, J.T., Deleon, V.R. and Lele, S.R. (2002) The Promise of Geometric Morphometrics. Yearbook of Physical Anthropology, 45, 63-91. http://dx.doi.org/10.1002/ajpa.10174

[12] Bookstein, F.L. (1991) Morphometric Tools for Landmark Data. Geometry and Biology. Cambridge University Press.

[13] Dryden, I.L. and Mardia, K.V. (1998) Statistical Analysis of Shape. John Wiley \& Sons, Chichester.

[14] Kudoh, H., Sugawara, T., Wu, S. and Murata, J. (2001) Morph-Specific Correlations between Floral Traits in a Distylous Ophiorrhiza napoensis (Rubiaceae) Population in Southern China. Journal of Tropical Ecology, 17, 719-728. http://dx.doi.org/10.1017/S0266467401001535

[15] Ornelas, J.F., Jiménez, L., González, C. and Hernández, A. (2004) Reproductive Ecology of Distylous Palicourea padifolia (Rubiaceae) in a Tropical Montane Forest. I. Hummingbirds' Effectiveness as Pollen Vectors. American Journal of Botany, 91, 1052-1060. http://dx.doi.org/10.3732/ajb.91.7.1052

[16] Ornelas, J.F., González, C., Jiménez, L., Lara, C. and Martínez, A.J. (2004) Reproductive Ecology of Distylous Palicourea padifolia (Rubiaceae) in a Tropical Montane Forest. II. Attracting and Rewarding Mutualistic and Antagonistic Visitors. American Journal of Botany, 91, 1061-1069. http://dx.doi.org/10.3732/ajb.91.7.1061

[17] Zelditch, M.L., Swiderski, D.L., Sheets, H.D. and Fink, W.L. (2004) Geometric Morphometrics for Biologists: A Primer. Elseviere Academic Press, New York. http://www2.canisius.edu/ sheets/morphsoft.html

[18] Rohlf, F.J. (2004) TpsDig Version 1.4. Department of Ecology and Evolution. State University of New York at Stony Brook, New York. http://life.bio.sunysb.edu/morph/index.html

[19] Sheets, H.D. (2004) IMP Software Series. Buffalo, Canisius College, New York. http://www.canisius.edu/ sheets/morphsoft.html

[20] Rohlf, F.J. and Slice, D. (1990) Extensions of the Procrustes Method for the Optimal Sperimposition of Landmarks. Systematic Zoology, 39, 40-59. http://dx.doi.org/10.2307/2992207

[21] Slice, D. (2001) Landmarks Aligned by Procrustes Analysis Do Not Lie in Kendall's Shape Space. Systematic Biology, 50, 141-149. http://dx.doi.org/10.1080/10635150119110

[22] Crawley, M.J. (2005) Statistics: An Introduction Using R. John Wiley \& Sons, Chichester. http://dx.doi.org/10.1002/9781119941750

[23] R Development Core Team (2009) R: A Language and Environment for Statistical Computing R. Foundation for Statistical Computing, Vienna.

[24] Pailler, T. and Thompson, J.D. (1997) Distyly and Variation in Heteromorphic Incompatibility in Gaertnera vaginata (Rubiaceae) Endemic to La Reunion Island. American Journal of Botany, 84, 315-327. http://dx.doi.org/10.2307/2446005

[25] Faivre, A.E. and McDade, L.A. (2001) Population-Level Variation in the Expression of Heterostyly in Three Species of Rubiaceae: Does Reciprocal Placement of Anthers and Stigmas Characterize Heterostyly? American Journal of Botany, 88, 841-853. http://dx.doi.org/10.2307/2657036

[26] Hernández-Ramírez, A.M. (2012) Distyly, Floral Visitors, and Fructification in 2 Natural Populations of Psychotria 
nervosa (Rubiaceae). Ecoscience, 19, 133-139. http://dx.doi.org/10.2980/19-2-3452

[27] Richards, J.H. and Barrett, S.C.H. (1992) The Development of Heterostyly. In: Barrett, S.C.H., Ed., Evolution and Function of Heterostyly, Springer-Verlag, Berlin, 85-127. http://dx.doi.org/10.1007/978-3-642-86656-2_4

[28] Dulberger, R. (1992) Floral Polymorphism and Their Functional Significance in the Heterostylous Syndrome. In: Barrett, S.C.H., Ed., Evolution and Function of Heterostyly, Springer Verlag, New York, 41-84. http://dx.doi.org/10.1007/978-3-642-86656-2_3 